To cite this article: Çaycı YT, Avan T, Bilgin K, Birinci A. Alt solunum yolu örneklerinden izole edilen Streptococcus Pneumoniae, Haemophilus İnfluenzae ve Moraxella Catarrhalis suşlarının antibiyotik duyarlılığının değerlendirilmesi. Turk J Clin Lab 2019; 10: $277-282$.

- Orjinal Makale

\title{
Alt solunum yolu örneklerinden izole edilen Streptococcus pneumoniae, Haemophilus influenzae ve Moraxella catarrhalis suşlarının antibiyotik duyarlılığının değerlendirilmesi
}

\section{Evaluation Of Antibiotic Susceptibility Of Streptococcus pneumoniae, Haemophilus influenzae and Moraxella catarrhalis Isolated From Lower Respiratory Tract Specimens}

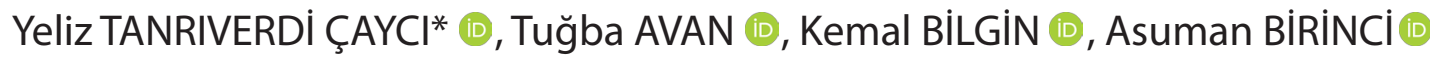

Ondokuz Mayıs Üniversitesi Tıp Fakültesi, Tıbbi Mikrobiyoloji Anabilim dalı, Samsun/TÜRKIYE

\begin{abstract}
Öz
Amaç: Bu çalışmada hastanemizin ayaktan ve yatarak takip edilen hastaların alt solunum yolu örneklerinden izole edilen ve solunum yolu enfeksiyonlarının en önemli enfeksiyon etkenleri olan Haemophilus influenzae, Moraxella catarrhalis ve Streptococcus pneumoniae suşlarının antibiyotik duyarlılık oranlarının belirlenmesi ve ampirik antibiyotik tedavisine yol göstermesi amaçlanmıştır.
\end{abstract}

Gereç ve Yöntemler: Ondokuz Mayıs Üniversitesi Tıp Fakültesi Hastanesi Tıbbi Mikrobiyooji Laboratuvarı́na 20152017 yıllarında çeşitli kliniklerden gönderilen alt solunum yolu örnekleri retrospektif olarak incelenmiştir. İzolatların tanımlanması Vitek MS (Biomerieux, Fransa) cihazı; antibiyotik duyarlılıkları Vitek 2 Compact (Biomerieux, Fransa) cihazı ve Mueller-Hinton Fastidious (Biomerieux, Fransa) agarda disk difüzyon yöntemi ile belirlenmiştir. Elde edilen duyarlılık oranları EUCAST (European Committee on Antimicrobial Susceptibility Testing) kriterlerine göre değerlendirilmiştir

Bulgular: Alt solunum yolları örneklerinden izole edilen 2427 adet suş retrospektif olarak incelendi. Streptococcus pneumoniae izolatlarına karşı \%67 penisilin, \%58 eritromisin direnci; Moraxella catarrhalis'e \%9 eritromisin, \%9 sefotaksim, $\% 3$ seftriakson direnci; Haemophilus influenzae'e \%92 eritromisin \%33 sefotaksim direnci saptanmıştır.

Sonuç: Alt solunum yolunun en sık izole edilen bu üç bakteriyel patojene karşı rutinde kullanılan antibiyotiklere karşı her geçen gün direnç artmaktadır. Etken belirlendikten sonra antibiyotik duyarlılık testlerinin yapılması tedavinin yönlendirilmesi açısından önemlidir.

Anahtar kelimeler: Haemophilus influenzae; Moraxella catarrhalis; Streptococcus pneumoniae; antibiyotik; direnç; alt solunum yolu enfeksiyonu

Sorumlu Yazar*: Yeliz Tanrıverdi Çaycı, Ondokuz Mayıs Üniversitesi Tıp Fakültesi, Tıbbi Mikrobiyoloji Anabilim dalı, Samsun/TÜRKIYE E-posta: yeliztanriverdi@gmail.com ORCID: 0000-0002-9251-1953

Gönderim: 08.05.2018 Kabul: 12.08.2018

Doi: $10.18663 /$ tjcl.421833 


\section{Abstract}

Aim: In this study, it was aimed to determine antibiotic susceptibility rates of Haemophilus influenzae, Moraxella catarrhalis and Streptococcus pneumoniae strains isolated from lower respiratory tract samples of hospitalized patients and to guide empirical antibiotic treatment of respiratory tract infections.

Material and Methods: The lower respiratory tract samples sent from various clinics to the Ondokuz Mayıs University Medical Faculty Hospital Medical Microbiology Laboratory in 2015-2017 were retrospectively examined. Identification of isolates Vitek MS (Biomerieux, France) device; antibiotic susceptibilities were determined by the Vitek 2 Compact (Biomerieux, France) instrument and disk diffusion method in Mueller-Hinton Fastidious (Biomerieux, France) agar. The sensitivity ratios obtained were evaluated according to EUCAST (European Committee on Antimicrobial Susceptibility Testing) criteria

Results: A total of 2427 strains isolated from lower respiratory tract specimens were examined retrospectively. $67 \%$ penicillin, $58 \%$ erythromycin resistance against Streptococcus pneumoniae isolates; $9 \%$ erythromycin, $9 \%$ cefotaxime, $3 \%$ ceftriaxone resistance to Moraxella catarrhalis; Haemophilus influenzae had $92 \%$ erythromycin and $33 \%$ cefotaxime resistance.

Conclusion: Resistance is increasing day by day against antibiotics used in routine against these three bacterial pathogens most commonly isolated in lower respiratory tract. Antibiotic susceptibility tests should be performed after the agent has been identified in order to direct treatment.

Keywords: Haemophilus influenzae; Moraxella catarrhalis; Streptococcus pneumoniae; antibiotic resistance; lower respiratory tract infection

\section{Giriş}

Haemophilus influenzae, Moraxella catarrhalis, Streptococcus pneumoniae insan üst solunum yolu florasında bulunmasına rağmen alt solunum yolu enfeksiyonlarından da sıklıkla izole edilen bakteriyel etkenlerdir [1].

S. pneumoniae, kapsüllü uzamış veya lanset şeklinde Gram pozitif koktur ve pnömoni, sinüzit, orta kulak iltihabı, menenjit ve bakteriyemiye neden olmaktadır. Antimikrobiyal direnç gittikçe yaygınlaşsada, duyarlı olan suşlarda penisilin ilk seçilecek ilaçtır. Penisilin grubu antibiyotiklerin uzun yıllar boyunca tedavi seçeneği olarak yaygın bir şekilde kullanılması sebebiyle, bakterilerin penisilinlere duyarlılık durumlarının takibi önem kazanmaktadır [2]. Penisilin bağlayan proteinlerde (PBP1A, PBP2X, PBP2B) meydana gelen yapısal değişiklikler nedeni ile penisiline karşı direnç gelişebilmektedir [3]. Ancak penisilin yanında diğer antibiyotiklere karşıda giderek artan direnç gelişimi görülebilmektdir. Özellikle solunum yolları enfeksiyonları tedavisinde tercih edilen makrolidlere karşı diren $\neg c ̧$ gelişmesinde iki mekanizma bulunmaktadır; bunlardan biri erm genleri tarafından kodlanan ribozomal metilaz ve diğeri mef genleri tarafından kodlanan makrolid efluks pompalarıdır $[4,5]$.

$\mathrm{H}$. influenzae fakültatif anaerob, ufak pleomorfik Gram negatif basil ve kokobasil şeklindedir. Başlıca menenjit, epiglottit, pnömoniye neden olmaktadır [4]. Birçok köken ampisiline karşı dirençlidir. Aminopenisilinlere karşı direnç $\beta$-laktamaz üretimi ve penisilin bağlayan proteinlerin (PBP3) aminoasitlerinde meydana gelen yapısal değişikler nedeni ile oluşmaktadır $[6,7]$. M. catarrhalis zorunlu aerob, oksidaz pozitif, Gram negatif diplokoktur. $\mathrm{Bu}$ organizma bronşit, bronkopnömoni, sinüzit ve orta kulak iltihabına neden olmaktadır. Ayrıca bu organizma immün sistemi baskılanmış hastalarda ciddi, hayatı tehdit eden sepsis, menenjit ve endokardit gibi infeksiyonlara yol açabilen fırsatçı bir patojen olarak karşımıza çıkmaktadır [8]. 1970'li yılların başında M. catarrhalis izolatları penisilinler ve tetrasiklinler dahil olmak üzere, solunum sitemi hastalıklarında kullanılan tüm antibiyotiklere duyarlı iken günümüzde çeşitli antibiyotiklere karşı direnç tedavide sıkıntılara neden olmaktadır. M. catarrhalis izolatlarında en önemli direnç problemi BRO betalaktamazlarının varlığıdır. $\mathrm{Bu}$ betalaktamazlar BRO-1 ve BRO-2 olarak tanımlanan, fenotipi benzer iki enzimden oluşmuştur. BRO-1'in BRO2'ye göre iki-üç kat fazla üretildiği gösterilmiştir. İzolatların çoğunda beta laktamaz üretimine bağlı penisiline direnci görülmekle beraber sefalosporinlere, eritromisine, tetrasikline, trimetoprim-sülfametaksazole, penisiline ve beta laktamaz kombinasyonlarına duyarlıdırlar $[4,8]$.

Bu çalışmada hastanemizde alt solunum yolları örneklerinden izole edilen $\mathrm{S}$. pneumoniae, $\mathrm{H}$. influenzae ve $\mathrm{M}$. catarrhalis suşlarının son üç yılda değişen direnç oranlarının belirlenmesi amaçlanmıştır. 


\section{Gereç ve Yöntemler}

Ondokuz Mayıs Üniversitesi Tıp Fakültesi mikrobiyoloji laboratuvarına 2015-2017 yılları arasında çeşitli kliniklerden gönderilen 2427 adet alt solunum yolları örneklerinden (balgam, bronkoalveolar lavaj (BAL), protected brush specimen (PBS) ve trakeal aspirat) izole edilen toplam 333 adet (S. pneumoniae $(n=72), H$. influenzae $(n=226)$ ve M. catarrhalis $(n=35))$ izolat çalışmaya dâhil edilmiştir. Çalışılan bakterilerin klinik örneklere göre dağılımı Tablo-1'de belirtilmiştir. Balgam örneklerinde gram boyalı preparatta $>25$ nötrofil ve $<10$ epitel hücre/saha olan örneklerde yoğun olan bakteri örnekleri değerlendirilmeye alınmıştır.

\begin{tabular}{l|c|c|c|c|}
\hline \multicolumn{5}{|c|}{ Tablo 1. Bakterilerin klinik örneklere göre dağılımı. } \\
\hline & H. influenzae & M. catarrhalis & S. pneumoniae & Toplam \\
\hline BAL & 6 & 1 & 4 & 11 \\
\hline Balgam & 197 & 32 & 54 & 283 \\
\hline PBS & 2 & 0 & 2 & 4 \\
\hline $\begin{array}{l}\text { Trakeal } \\
\text { Aspirat }\end{array}$ & 21 & 2 & 12 & 35 \\
$\begin{array}{l}\text { Genel } \\
\text { Toplam }\end{array}$ & 226 & 35 & 72 & 333 \\
\hline
\end{tabular}

Gelen örnekler \%5'lik koyun kanlı agar, çikolata agar ve EMB (Eozin Metilen Blue) agar besiyerine ekilmiştir. Ekimi yapılan plaklar \%5 CO2'li ortamda $35 \pm 1^{\circ} \mathrm{C}$ 'de 24 saat inkübe edildi. İnkübasyon sonunda üreyen örneklerin gram boyama, koloni morfolojisi, katalaz ve oksidaz test sonuçlarına göre ön değerlendirilmesi yapılmıştır. Sonrasında izolatların tanımlanmasında Vitek MS (Biomerieux, Fransa) cihazı kullanılmıştır. S. pneumoniae'nın ampisilin, eritromisin, levofloksasin, linezolid, penisilin, seftriakson, sefotaksim, teikoplanin, ve vankomisin duyarlılığı Vitek 2 Compact (Biomerieux, Fransa) cihazı ile tespit edilmiştir. $\mathrm{H}$. influenzae'nın ampisilin, amoksisilin-klavulanat, eritromisin, seftriakson, sefotaksim ve siprofloksasin duyarlılığı MuellerHinton Fastidious (Biomerieux, Fransa) agarda disk difüzyon yöntemi ile çalışılmıştır. M. catarrhalis'in amoksisilinklavulanat, eritromisin, meropenem, seftriakson, sefotaksim ve siprofloksasin \%5 koyun kanlı Mueller-Hinton Fastidious (Biomerieux, Fransa) agarda disk difüzyon yöntemi ile çalışılmıştır. Elde edilen duyarlılık oranları EUCAST (European Committee on Antimicrobial Susceptibility Testing) kriterlerine göre değerlendirilmiştir $[9,10,11]$.

\section{Bulgular}

\section{S. pneumoniae}

Toplam 72 adet S. pneumoniae suşu ( 2015 yılında $n=24,2016$ yılında $n=23,2017$ yılında $n=25$ ) çalışmaya dahil edilmiştir. S. pneumoniae izolatlarının tüm antibiyotiklere direnç oranları Tablo-2 de yer almaktadır. En yüksek direnç oranı penisiline (\%67) karşı saptanırken, linezolid, teikoplanin ve vankomisine karşı direnç tespit edilmemiştir. Yıllara göre değişim incelendiğinde linezolid, teikoplanin ve vankomisine karşı direnç saptanmamış olup yıllara göre antibiyotik dirençlilik oranları tablo-3 deki gibidir.

\begin{tabular}{|c|c|c|c|}
\hline & DUYARLI & DIRENÇLİ & TOPLAM \\
\hline Ampisilin & $26(58)$ & $19(42)$ & 45 \\
\hline Eritomisin & $29(42)$ & $40(58)$ & 69 \\
\hline Levofloksasin & $66(93)$ & $5(7)$ & 71 \\
\hline Linezolid & $70(100)$ & 0 & 70 \\
\hline Penisilin & $10(33)$ & $20(67)$ & 30 \\
\hline Seftriakson & $56(82)$ & $12(18)$ & 68 \\
\hline Sefotaksim & $55(77)$ & $16(23)$ & 71 \\
\hline Teikoplanin & $10(100)$ & 0 & 10 \\
\hline Vankomisin & $72(100)$ & 0 & 72 \\
\hline
\end{tabular}

\begin{tabular}{|c|c|c|c|}
\hline & 2015 & 2016 & 2017 \\
\hline Ampisilin & $1(2)$ & $10(22)$ & $8(18)$ \\
\hline Eritomisin & $11(16)$ & $17(25)$ & $12(17)$ \\
\hline Levofloksasin & 0 & $2(3)$ & $3(4)$ \\
\hline Linezolid & 0 & 0 & 0 \\
\hline Penisilin & 0 & $10(34)$ & $10(34)$ \\
\hline Seftriakson & $2(3)$ & $6(9)$ & $4(6)$ \\
\hline Sefotaksim & $3(4)$ & $8(12)$ & $5(5)$ \\
\hline Teikoplanin & 0 & 0 & 0 \\
\hline Vankomisin & 0 & 0 & 0 \\
\hline
\end{tabular}

\section{H.influenzae}

Toplam 226 adet H. influenzae suşu ( 2015 yılında $n=82,2016$ yılında $n=60,2017$ yılında $n=84$ ) çalışmaya dâhil edilmiştir. $\mathrm{H}$. influenzae izolatlarının tüm antibiyotiklere direnç oranları tablo-4 de yer almaktadır. En çok direnç eritromisine (\%92) karşı görülürken yıllara göre antibiyotik direnci incelendiğinde amoksisilin-klavulanat ve siprofloksasinde direnç artışı gözlenirken eritomisin de anlamlı bir değişiklik saptanmamıştır. Buna karşın ampisilin ve seftriaksonda direnç oranlarında azalma gözlenmiştir. Yıllara göre ise antibiyotik dirençlilik oranları tablo-5 deki gibidir. 


\begin{tabular}{|c|c|c|c|}
\hline & DUYARLI & DIRENÇLi & TOPLAM \\
\hline $\begin{array}{l}\text { Amoksisilin/klavu- } \\
\text { lanik asit }\end{array}$ & $35(97)$ & 1(3) & 36 \\
\hline Ampisilin & $144(65)$ & $78(35)$ & 222 \\
\hline Eritromisin & 14(8) & $157(92)$ & 171 \\
\hline Seftriakson & $220(98)$ & $4(2)$ & 224 \\
\hline Sefotaksim & $149(67)$ & $74(33)$ & 223 \\
\hline Siprofloksasin & 164(96) & $6(4)$ & 170 \\
\hline \multicolumn{4}{|c|}{$\begin{array}{l}\text { Tablo 5. H. influenzae izolatlarının antibiyotik dirençlerinin } \\
\text { yıllara göre dağııımı [n (\%)]. }\end{array}$} \\
\hline & 2015 & 2016 & 2017 \\
\hline Amoksisilin/klavulanik asi & 0 & 0 & $1(3)$ \\
\hline Ampisilin & $37(17)$ & $22(10)$ & 19(9) \\
\hline Eritromisin & 25(15) & $53(31)$ & $79(46)$ \\
\hline Seftriakson & $2(1)$ & $1(0.5)$ & $1(0.5)$ \\
\hline Sefotaksim & $21(9)$ & $27(12)$ & $26(12)$ \\
\hline Siprofloksasin & 0 & 0 & $6(4)$ \\
\hline
\end{tabular}

\section{M.catarrhalis}

Toplam 35 adet M. catarrhalis suşu ( 2015 yılında $n=9,2016$ yılında $n=12,2017$ yılında $n=14$ ) çalışmaya dâhil edilmiştir. M. catarrhalis izolatlarının tüm antibiyotiklere direnç oranları tablo-6 de yer almaktadır. En çok direnç eritromisin (\%9) ve sefotaksime (\%9) karşı görülürken birçok antibiyotiğe duyarlı olarak tespit edilmiştir. Yıllara göre direnç oranları incelendiğinde amoksisilin-klavulonik asit ve meropenemde hiç duyarlılık gelişmediği gözlenmiştir. Eritromisin, sefotaksim ve seftriaksonda direnç artışı gözlenmektedir. Yıllara göre ise antibiyotik dirençlilik oranları tablo-7'da verilmiştir.

\begin{tabular}{|c|c|c|c|}
\hline & DUYARLI & DIRENÇLi & TOPLAM \\
\hline Amoksisilin/klavulanik asit & $35(100)$ & 0 & 35 \\
\hline Eritromisin & $31(91)$ & $3(9)$ & 34 \\
\hline Meropenem & $35(100)$ & 0 & 35 \\
\hline Sefotaksim & $30(91)$ & $3(9)$ & 33 \\
\hline Seftriakson & $34(97)$ & 1(3) & 35 \\
\hline Siprofloksasin & $34(97)$ & $1(3)$ & 35 \\
\hline
\end{tabular}

\begin{tabular}{|c|c|c|c|}
\hline & 2015 & 2016 & 2017 \\
\hline Amoksisilin/klavulanik asit & 0 & 0 & 0 \\
\hline Eritromisin & 0 & 1(3) & $2(6)$ \\
\hline Meropenem & 0 & 0 & 0 \\
\hline Sefotaksim & 0 & 0 & $3(9)$ \\
\hline Seftriakson & 0 & 0 & $1(3)$ \\
\hline Siprofloksasin & 0 & 1(3) & 0 \\
\hline
\end{tabular}

\section{Tartışma}

Son yıllarda $S$. pneumoniae, $H$. influenzae ve $M$. catarrhalis izolatlarının antibiyotiklere karşı gösterdiği direnç tüm dünyada hızla artmakta olduğu dikkat çekmektedir. S. pneumoniae için 2002-2003 yılları arasında izole edilen örneklerden yapılan çok uluslu bir çalışmada ülkeler arasında belirgin farklılıklar izlenmekle beraber penisilin direncinin \%0-79,2 ve eritromisin direncinin \%4-66 arasında değiştiği saptanmıştır [12]. Çin'de 2016 yılında yapılan çalışmaya göre ise aynı ülke sınırları içinde farklı şehirlerde direnç oranlarının değişebileceği belirtilmiştir. Yapılan bu çalışmada S. pneumoniae suşları; penisiline duyarlı S. pneumoniae (PSSP), penisiline orta duyarlı S. pneumoniae (PISP) ve penisiline dirençli S. pneumoniae (PRSP) olamak üzere üç fenotipik kalıp olarak değerlendirilmiştir. Tüm $\beta$-laktamların MiK50 ve MiK90 değerleri, penisiline duyarlı olmayan S. pneumoniae izolatlarına karşı daha yüksek (PNSSP); PSSP izolatlarında ise daha düşük olarak bulunmuştur. PISP suşlarının çoğunluğu, \%90 duyarlılık oranları ile amoksisilinklavulonat, seftriakson, kinolonlar ve kloramfenikole duyarlı iken; buna karşın PRSP'nin seftriakson ve amoksisilinklavulonata duyarlıık oranı sırasıyla $\% 51,1$ ve $\% 34,4$ olarak saptanmıştır. PRSP izolatları ile ilgili olarak, sefuroksim, sefaklor, SXT, makrolidler ve tetrasiklin düşük aktivite göstermiştir. PRSP izolatlarının çoğunda levofloksasin direnç oranı \%1,2 olarak saptanmıştır. Farklı merkezlerde PNSSP oranlarının \%25-72,2 arasında değiştiği belirtilmiştir [13]. İtalya'da 2017 yılında yapılan çalışmada 2014-2015 yılları arasında çocuk hastaların solunum yollarından izole edilen $\mathrm{S}$. pneumoniae suşlarında ise penisilin G $(\% 31,3)$ ve sefalosporinler $(\% 18,7-3,13)$ dahil olmak üzere $\beta$-laktam antibiyotiklere karşı yüksek direnç oranları görülmüştür. Aynı çalışmada tüm izolatlar sülfametoksazoltrimetoprim'e (\%100) dirençli iken izolatların sadece \%50'si azitromisin'e duyarlı, tüm izolatlar ise fluorokinolon antibiyotiklerine (levofloksasin, ofloksasin) ve klindamisine (MIC $90=0,19 \mathrm{mg} / \mathrm{L}$ ) duyarlı olduğu bulunmuştur [17]. Fransa'da S. pneumoniae'da EUCAST eşik değerlerine göre, penisilin direnç oranı 2004-2012 yılları arasında \% 3,2 olarak bildirilmiştir [14]. Yunanistan'da 2009-2010 yıllarında solunum yolu enfeksiyonlarından izole edilen S. pneumoniae suşlarında $\% 17,6$ olan oral penisilin direncinin 2011-2012 yıllarında $\% 6,4$ 'e gerilediğini, orta duyarlı izolatların oranlarının ise yükseldiği görülmüştür $(\% 24,3-\% 30,4)$ [15]. Mamishi ve ark. içinde Türkiye'nin de olduğu, Asya ülkelerinde S. pneumoniae izolatlarında penisilin direncini saptadıkları bir meta-analiz raporunda, penisilin direncinin tüm Asya ülkeleri için büyük bir 
endişe kaynağı olabileceğini belirtmektedirler [16]. Ülkemizde ise Alışkan ve ark. yaptığı çalışmada 2012-2015 yılları arasında izole edilen S. pneumoniae suşlarını kapsayan 2016'da yayınlanan çalışmalarında oral penisilin direnç oranı \%24,6, eritromisin direnci ise \%36,2 olarak saptanmışlardır [17]. Beşli ve ark.'nın çalışmalarında 2012-2014 yılları arasında izole edilen S. pneumoniae suşlarındaki duyarlılık oranları ise penisilin için \%92,4, eritromisin için \%45,7 olarak bildirilmiştir [18].

H.influenzae, S.penumoniae'dan sonra solunum yolunun önemli patojenlerinden biridir. Ampisilin duyarlılığı Fransa'da yapılan 2004-2012 yıllarını kapsayan çok merkezli çalışmada \%75,6; ABD'de 2008-2010 yılları arasında yapılan çalışmada \%73,7 olarak tespit edilmiştir [14]. İtalya'da 2017 yılında yapılan çalışmada 2014-2015 yılları arasında çocuk hastaların solunum yollarından izole edilen $\mathrm{H}$. influenzae suşlarında ampisiline \% 10,5, sefaklora \%11,2, direnç oranları gözlenirken amoksisilinklavulonat ve siprıfloksasine direnç gelişimi gözlenmemiştir. Tüm ampisiline dirençli izolatlarında $\beta$-laktamaz üretimi gözlenmiş̧tir [19]. 2002-2003 yılları arasında izole edilen örneklerden yapılan çok uluslu bir çalışmada $\beta$-laktamaz üretimi $\mathrm{H}$. influenzae için \%0-39 arasında saptanmıştır [12]. Çin'de 2016 yılında yapılan çalışmaya göre ampisilin için \%35 direnç oranı saptanırken seftriakson, levofloksasin, moksifloksasin, azitromisin ve tetrasiklin için yüksek duyarlılık oranları saptanmıştır (>\%90). Bu çalışmada, $294 \mathrm{H}$. influenzae izolatı arasında, 91 (\%31) suşun $\beta$-laktamaz ürettiği saptanmıştır. $\beta$-laktamaz negatif ampisiline dirençli saptanan bazı suşlarda ampisilin, amoksisilin-klavulonat, sefaklor ve sefuroksime direnç \%100 olarak bulunmuştur [13]. Ülkemizde bu konuda yapılan çalışmalar incelendiğinde Alışkan ve ark. ampisilin direncini \%24,3 [17], İlki ve ark. \%3.3 [21], Gür ve ark. $\% 8,8$ [20] olarak bildirmişlerdir. Çalışmamızda ise ampisilin direnci \%35 olup diğer çalışmalara göre yüksek; Çin'de yapılan çalışma ile aynı olduğu tespit edilmiştir.

M. catarrhalis suşlarında betalaktam antibiyotiklere karşı hızla artan direnç söz konusudur. M. catarrhalis $\beta$-laktamaz üretimi 2002-2003 yılları arasında izole edilen örneklerden yapılan çok uluslu bir çalışmada \%80-100 arasında saptanmıştır [12]. 2016 yılında Çin'de yapılan çalışmaya göre antimikrobik ajanların çoğu, M. catarrhalis izolatlarına karşı >\%90 duyarlııık oranları gösterirken; sefuroksim, sefaklor, SXT, kloramfenikol ve tetrasiklin, M. catarrhalis'e daha düşük duyarlılık oranları gözlenmiştir. Bu çalışmada $M$. catarrhalis izolatlarının \% 87,1 'inde $\beta$-laktamaz üretimi gözlenmiştir [13]. Italya'da yapılan çalışmada 2014-2015 yılları arasında çocuk hastaların solunum yollarından izole edilen $\mathrm{M}$. catarrhalis izolatlarında test edilen florokinolonlar düşük MiK90 (0,094 mg / L) değerleri (sırasıyla levofloksasin ve siprofloksasin için duyarlılık \%100 ve \%95.2 ) saptanmıştır. Test edilen izolatlar arasında \% 95,7 'si sefuroksim ve sefaklora duyarlı iken; $\beta$-laktamaz için pozitif M. catarrhalis izolatlarının \%91,3'ü ampisiline dirençli bulunmuştur [19]. Bu konuda yapılan çalışmalarda Şener ve ark. M. catarrhalis eritromisin direncini \%8 saptarken amoksisilin-klavulanik asit, sefotaksim ve siprofloksasinde hiç direnç saptamadıklarını bildirmişlerdir [22]. Şenol ve arkadaşları ise siprofloksasin direncini \%9 bildirirken seftriaksonda hiç direnç olmadığını bildirmişlerdir [1]. Çalışmamızda ise eritromisin direnci \%9 tespit edilmiş olup diğer çalışmalarla uyumlu bulunmuştur. Siprofloksasin ise \%3 oranında direnç olup diğer çalışmalara göre daha yüksek gözlenmiştir. Sefotaksim direnç oranı \%9, seftriakson direç oranı ise $\% 3$ tespit edilmiştir.

\section{Sonuç}

Alt solunum yolunun en sık izole edilen bu üç bakteriyel patojene karşı rutinde kullanılan antibiyotiklere karşı her geçen gün direnç artmaktadır. Etken belirlendikten sonra antibiyotik duyarlılık testlerinin yapılması tedavinin yönlendirilmesi açısından önemlidir.

\section{Çıkar çatışması / finansal destek beyanı}

Bu yazıdaki hiçbir yazarın herhangi bir çıkar çatışması yoktur. Yazının herhangi bir finansal desteği yoktur.

\section{Kaynaklar}

1. Şenol G, Eriş F. Akciğer Enfeksiyonlarında Haemophilus influenzae, Moraxella catarrhalis ve Streptococcus pneumoniae suşlarının izolasyon oranları ve antibiyotiklere Direnci. Toraks Dergisi 2000; 1: 46-49.

2. Golden AR, Rosenthal M, Fultz B, Nichol KA, Adam HJ, Gilmour MW et al. Characterization of MDR and XDR Streptococcus pneumoniae in Canada, 2007-13. J Antimicrob Chemother 2015; 70: 2199-202.

3. Ip M, Ang I, Liyanapathirana V, Ma H, Lai R. Genetic analyses of penicillin binding protein determinants in multidrug-resistant streptococcus pneumoniae serogroup 19 CC320/ 271 clone with high-level resistance to third-generation cephalosporins. Antimicrob Agents Chemother 2015; 59: 4040-45.

4. Murray P, Rosenthal K, Pfaller M: Tıbbi Mikrobiyoloji kitabı, Ankara 2014. 
5. Hoban DJ, Doern GV, Fluit AC, Roussel-Delvallez $M$, Jones RN. Worldwide prevalence of antimicro $\neg$ bial resistance in Streptococcus pneumoniae, Haemophilus influenzae, and Moraxella catarrhaᄀlis in the SENTRY antimicrobial surveillance prog $\neg$ ram 1997-1999. Clin Infect Dis 2001; 32: 81-83.

6. Fluit AC, Florijn A, Verhoef J, Milatovic D. Susceptibility of European beta-lactamase-positive and negative Haemophilus influenzae isolates from the periods 1997/1998 and 2002/2003. J Antimicrob Chemother 2005; 56: 133-38.

7. García-Cobos S, Moscoso M, Pumarola F, Arroyo M, Lara N, PérezVázquez $M$ et al. Frequent carriage of resistance mechanisms to $\beta$-lactams and biofilm formation in Haemophilus influenzae causing treatment failure and recurrent otitis media in young children. J Antimicrob Chemother 2014; 69: 2394-9.

8. Ustaçelebi Ş Temel ve Klinik Mikrobiyoloji kitabı, Güneş Kitapevi, 1999.

9. European Committee on Antimicrobial Susceptibility Testing (EUCAST)Breakpoint tables for interpretation of MICs and zone diameters. Version 5.0, http://www.eucast.org (2015)

10. European Committee on Antimicrobial Susceptibility Testing (EUCAST). Breakpoint tables for interpretation of MICs and zone diameters. Version 6.0, http://www.eucast.org/fileadmin/ src/media/PDFs/EUCAST_files/Breakpoint_tables/v_6.0_ Breakpoint_table.pdf (2016)

11. European Committee on Antimicrobial Susceptibility Testing (EUCAST). Breakpoints tables for interpretation of MICs and zone diameters, Version 7.1. http://www.eucast.org (2017)

12. Beekmann S, Heilmanna K, Richtera S, Garcia-de-Lomasb J, Doerna G. Antimicrobial resistance in Streptococcus pneumoniae, Haemophilus influenzae, Moraxella catarrhalis and group A -haemolytic streptococci in 2002-2003. International Journal of Antimicrobial Agents 2005; 25: 148-56.

13. Zhang $\mathrm{Y}$, Zhang F,Wang $\mathrm{H}$ et al. Antimicrobial susceptibility of Streptococcus pneumoniae, Haemophilus influenzae and Moraxella catarrhalis isolated from community-acquired respiratory tract infections in China: Results from the CARTIPS Antimicrobial Surveillance Program. J Glob Antimicrob Resist 2016; 5: 36-41.
14. Cattoir V, Dowzicky MJ. A longitudinal assessment of antimicrobial susceptibility among important pathogens collected as part of the Tigecycline Evaluation and Surveillance Trial (T.E.S.T.) in France between 2004 and 2012. Antimicrob Resist Infect Control 2014; 3: 36.

15. Maraki S, Papadakis IS. Antimicrobial resistance trends among community-acquired respiratory tract pathogens in Greece, 2009-2012. Scientific World Journal 2014; 27: 941564.

16. Mamishi S, Moradkhani S, Mahmoudi S, Hosseinpour-Sadeghi R, Pourakbari B. Penicillin-Resistant trend of Streptococcus pneumoniae in Asia: a systematic review. Iran J Microbiol 2014; 6: 198-210.

17. Alışkan H, Çolakoğlu Ş, Göçmen J. Solunum yolu örneklerinden izole edilen streptococcus pneumoniae ve haemophilus influenzae suşlarının antibiyotiklere dirençlerinin belirlenmesi. Cukurova Med J 2016; 41: 201-7.

18. Beşli Y, Karatuna O, Akyar I. 2012-2014 Yıllarında Alt Solunum Yolu Örneklerinden İzole Edilen Streptococcus pneumoniae ve Haemophilus influenzae suşlarında antibiyotiklere Duyarlıı̆ın Yıllara ve Yaş Gruplarına Göre Değerlendirilmesi. ANKEM Derg 2015; 29: 114-21.

19. Camara M, Dieng A, Diop A et al. Antibiotic resistance of bacteria responsible of acute respiratory tract infections in children. Microbiologia Medica 2017; 32: 6489.

20. Gur D, Ozalp M, Sümerkan B et al. Prevalence of antimicrobial resistance in Haemophilus influenzae, Streptococcus pneumoniae, Moraxella catarrhalis and Streptococcus pyogenes: results of a multicentre study in Turkey. Int J Antimicrob Agents 2002; 19: 207-11.

21. Ilki A, Sağiroğlu P, Elgörmüş N, Söyletir G. Streptococcus pneumoniae ve Haemophilus influenzae izolatlarının antibiyotik duyarlılık paternlerindeki değişim: dört yıllık izlem. Mikrobiyol Bul 2010; 44: 169-75.

22. Şener B, Gür D, Sümerkant B et al. Haemophilus influenzae, Streptococcus pneumoniae, Moraxella catarrhalis and Streptococcus pyogenes'in çeşitli antibiyotiklere karşı in-vitro duyarlılıkları. Mikrobiyoloji Bült 1996; 30: 129-37. 